March 1999 • NREL/TP-540-25928

\title{
Advisor 2.0: A Second- Generation Advanced Vehicle Simulator for Systems Analysis
}

\author{
K. Wipke, M. Cuddy, D. Bharathan, \\ S. Burch, V. Johnson, A. Markel, and \\ S. Sprik
}




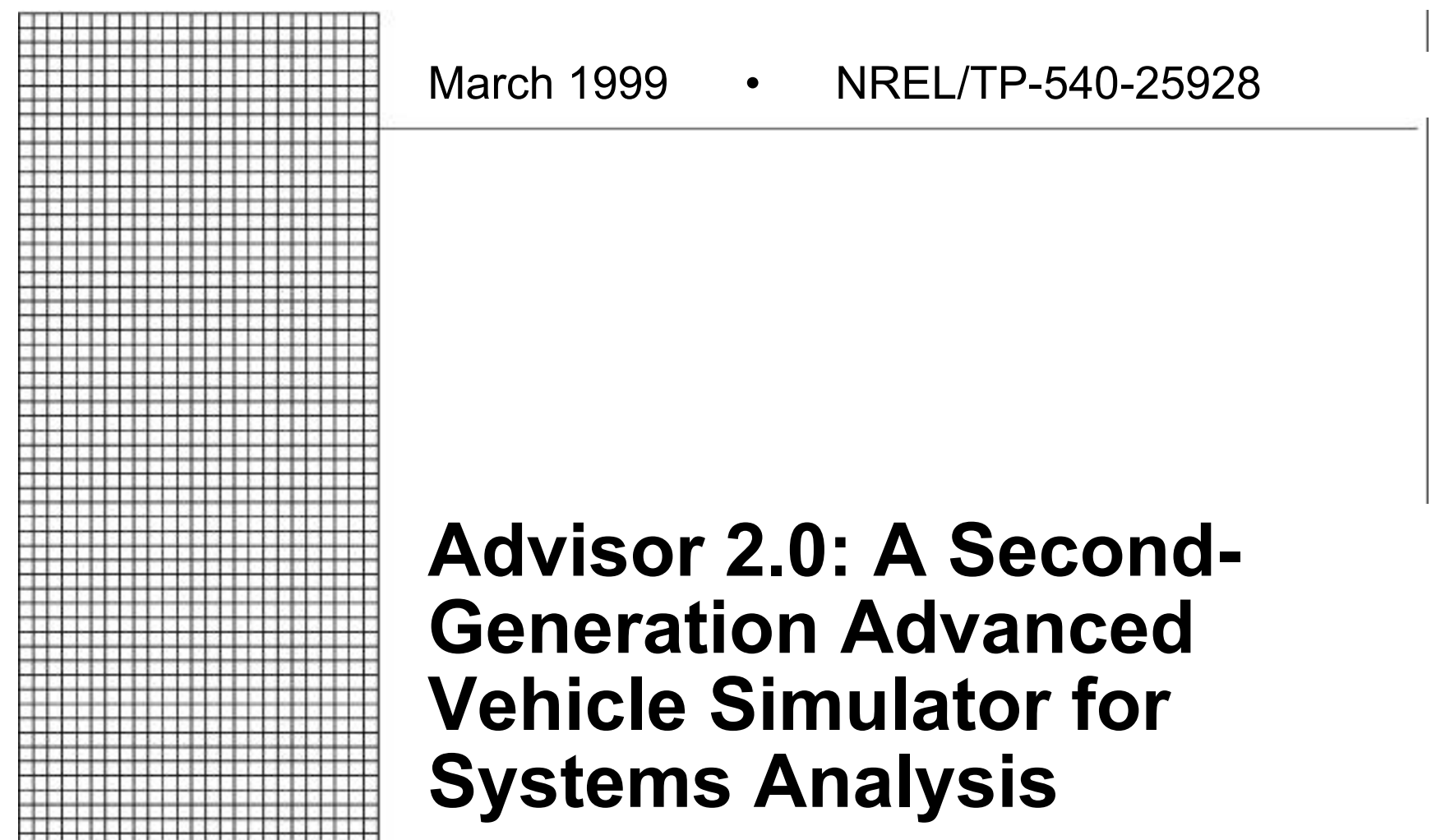

K. Wipke, M. Cuddy, D. Bharathan, S. Burch, V. Johnson, A. Markel, and S. Sprik

Prepared under Task No. HV916010

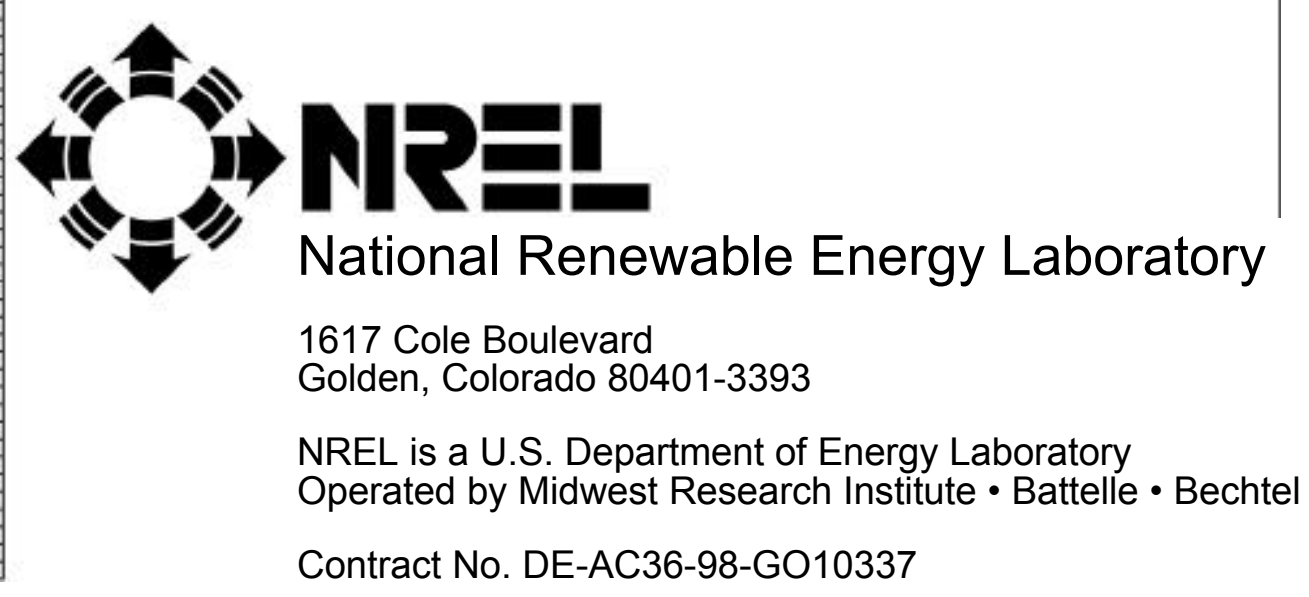




\section{NOTICE}

This report was prepared as an account of work sponsored by an agency of the United States government. Neither the United States government nor any agency thereof, nor any of their employees, makes any warranty, express or implied, or assumes any legal liability or responsibility for the accuracy, completeness, or usefulness of any information, apparatus, product, or process disclosed, or represents that its use would not infringe privately owned rights. Reference herein to any specific commercial product, process, or service by trade name, trademark, manufacturer, or otherwise does not necessarily constitute or imply its endorsement, recommendation, or favoring by the United States government or any agency thereof. The views and opinions of authors expressed herein do not necessarily state or reflect those of the United States government or any agency thereof.

Available to DOE and DOE contractors from:

Office of Scientific and Technical Information (OSTI)

P.O. Box 62

Oak Ridge, TN 37831

Prices available by calling $423-576-8401$

Available to the public from:

National Technical Information Service (NTIS)

U.S. Department of Commerce

5285 Port Royal Road

Springfield, VA 22161

703-605-6000 or 800-553-6847

or

DOE Information Bridge

http://www.doe.gov/bridge/home.html

Printed on paper containing at least $50 \%$ wastepaper, including $20 \%$ postconsumer waste 


\title{
ADVISOR 2.0: A Second-Generation Advanced Vehicle Simulator for Systems Analysis ${ }^{*}$
}

\author{
Keith Wipke, Matthew Cuddy, Desikan Bharathan, Steve Burch, \\ Valerie Johnson, Tony Markel, and Sam Sprik \\ National Renewable Energy Laboratory (NREL) \\ 1617 Cole Blvd. \\ Golden, CO 80401 \\ http://www.ctts.nrel.gov/analysis/
}

\begin{abstract}
The National Renewable Energy Laboratory has recently publicly released its second-generation advanced vehicle simulator called ADVISOR 2.0. This software program was initially developed four years ago, and after several years of in-house usage and evolution, this powerful tool is now available to the public through a new vehicle systems analysis World Wide Web page. ADVISOR has been applied to many different systems analysis problems, such as helping to develop the SAE J1711 test procedure for hybrid vehicles and helping to evaluate new technologies as part of the Partnership for a New Generation of Vehicles (PNGV) technology selection process. The model has been and will continue to be benchmarked and validated with other models and with real vehicle test data. After two months of being available on the Web, more than 100 users have downloaded ADVISOR. ADVISOR 2.0 has many new features, including an easy-to-use graphical user interface, a detailed exhaust aftertreatment thermal model, and complete browser-based documentation. Future work will include adding to the library of components available in ADVISOR, including optimization functionality, and linking with a more detailed fuel cell model.
\end{abstract}

\section{Introduction}

NREL's Advanced Vehicle Simulator, ADVISOR, was first developed in November 1994. It was designed as an analysis tool to assist the U.S. Department of Energy (DOE) in developing and understanding hybrid electric vehicles (HEVs) through the Hybrid Vehicle Propulsion System contracts with Ford, GM, and Chrysler. As the tool became more advanced and flexible, it has also been used by many other clients to understand the system-level interactions of hybrid and electric vehicle components.

ADVISOR was designed to analyze vehicle powertrains, focusing on power flows among the components. When it is used to follow a driving cycle, such as the Federal Urban Driving Schedule, its main outputs are fuel use and tailpipe emissions. It can also be used to simulate the vehicle in a maximum effort acceleration, where outputs are $0-60 \mathrm{mph}$ time or 40-60 mph time,

\footnotetext{
* Presented at the North American EV \& Infrastructure Conference and Exposition (NAEVI 98), December 3-4, 1998, Phoenix, Arizona.
} 
for example, or to determine the maximum road grade the vehicle can climb at some sustained speed.

In accordance with its design goals, ADVISOR approximates the continuous behavior of a vehicle as a series of discrete steps. During each step the components are assumed to be at steady state. This assumption allows the use of power-usage or efficiency maps for the components, which are derived from steady-state tests in the laboratory. This main assumption, however, does not allow investigation of detailed, short-duration drivetrain dynamics. For example, vibrations in the driveline and oscillations in electric fields are beyond ADVISOR's scope.

\section{Background: Applications of ADVISOR}

ADVISOR has been used successfully to evaluate many different conceptual vehicles and new test procedures and driving cycles. A few past and ongoing projects are described below.

\section{Evaluating the Draft SAE J1711 Hybrid Vehicle Test Procedure}

During the first half of 1998, NREL collaborated with the SAE J1711 Task Force to simulate a number of hypothetical vehicles on the draft test procedure called "SAE J1711: Recommended Practice for Measuring the Exhaust Emissions and Fuel Economy of Hybrid-Electric Vehicles." The test procedure is intended to measure HEV fuel use and emissions to allow fair comparisons among HEVs, electric vehicles (EVs), and conventional vehicles. Because hybrids, unlike EVs and conventional vehicles, have two energy sources that may be combined in many ways, it is particularly difficult to devise a robust test procedure. Evaluations of the test procedure were performed several years ago, before numerous significant changes were made to the test procedure. To address questions about this new procedure, NREL used ADVISOR to evaluate the procedure's robustness and provide feedback to the development committee.

To perform the analysis, data sets representing a number of vehicles were collected, based on vehicles that had either already been demonstrated or were under development. The performance of each vehicle on the draft SAE J1711 was then simulated using ADVISOR. The analysis uncovered some significant sensitivities to battery state-of-charge (SOC) in the predicted fuel economy and emissions, and laid the groundwork for further refinement of the draft SAE J1711 procedure [1]. A future enhancement will be to include the complicated SAE HEV test procedure in the library of available test procedures in ADVISOR.

\section{Selecting Technologies for the Continuation of PNGV}

During the third quarter of 1997, NREL worked with representatives of the Environmental Protection Agency; the Departments of Energy, Commerce, and Transportation; and the Office of the Vice President to estimate the performance of hybrid and conventional vehicles that would likely be feasible in the year 2004. This effort was to help meet a major Partnership for a New Generation of Vehicles (PNGV) milestone for 1997: selecting the likely technologies to be used in the year $2004 \mathrm{PNGV}$ concept car. 
To perform the analysis, industry and government experts were consulted to develop estimates of component performance, including "best case" and "conservative" estimates. These were compiled and run through a series of simulations with the aid of a powerful accounting control script that fed ADVISOR inputs, ran the simulation, and verified and filed its outputs.

As a result of this work, the industry and government teams of the PNGV came to substantial agreement on the prospects of various types of hybrid vehicles. A parallel compression-ignition direct injection (CIDI) hybrid was deemed the best near-term hybrid in terms of fuel economy, and only fuel cell-powered hybrids broke the $80 \mathrm{mpg}$ barrier [2].

\section{Many Organizations are Already Using ADVISOR 2.0}

Roughly 30 organizations were using the previous version of ADVISOR, but since ADVISOR 2.0 was released on September 15, more than 250 people have downloaded the new version of the software. More than 200 distinct companies or organizations are represented, with several new users being added each day.

The applications for which people use ADVISOR are as varied as the companies who are using it, but there are many common threads. ADVISOR is often used as a screening tool to evaluate many different design options, to get a feel for the size of the components that would be required for a given application, and to do sensitivity studies to look at the effect of varying parameters away from some baseline. Some suppliers are using ADVISOR to evaluate how well their components would perform in advanced vehicles, comparing their components with those in the ADVISOR library, or investigating whether changing their designs would open up a new market for their products. Although all of the major automobile manufacturers have their own proprietary simulation tools, many have also obtained ADVISOR to investigate other types of vehicle configurations.

\section{Validation and Benchmarking of ADVISOR}

The validation of ADVISOR to ensure its accuracy has been a high priority since its initial development. Beginning in 1995, NREL collaborated with representatives from industry and other national labs in a benchmarking exercise. When all participants used identical inputs, we found that ADVISOR's predictions closely matched those of industry. When the PNGV Systems Analysis Toolkit version 1.7 became available in April 1997, a benchmarking with that model confirmed similar results from both models for the cases studied.

In 1997, researchers at Virginia Polytechnic Institute validated ADVISOR using data from their award-winning FutureCar competition series hybrid entry. The researchers developed data files representing their vehicle and each of its components and modified the default control strategy to match their own. They then simulated the vehicle's performance on the vehicle's actual speed trace, and compared the ADVISOR-predicted fuel-use and battery energy-use with the measured values. They found agreement within the uncertainty of the measurements [3].

In order to validate the current version of ADVISOR even further, researchers at Argonne National Laboratory (ANL) are measuring the performance of various drivetrain components and 
then of the drivetrain system as a whole. This will allow a detailed validation of ADVISOR to be performed, and any discrepancies that are discovered to be resolved. Validated data sets on state-of-the-art CIDI engines will also be added to ADVISOR by Oak Ridge National Laboratory (ORNL) and ANL.

\section{What's New in Version 2.0?}

Version 2.0 of ADVISOR includes major improvements and updates since the last public release of ADVISOR, which was version 1.2.1 in April 1998. Here are highlights of the major new features you will find in ADVISOR 2.0, followed by an in-depth look at a few of these features:

- Easy-to-use graphical user interface to enable most systems analysis problems to be investigated through the graphical user interface (GUI)

- Exhaust aftertreatment system models, including thermal modeling of the entire exhaust system and tracking of particulate matter (PM) emissions

- Complete HTML (web-browser based) documentation including detailed block-diagram model descriptions and equations, algorithms behind the control strategies, complete listing of input and output variables, and a user's guide

- Autosizing routine to automatically size drivetrain components to meet user-defined acceleration and gradeability constraints

- Zero-delta battery state-of-charge (SOC) correction for fuel economy

- New component data files added to library, including state-of-the-art lead-acid battery data from Optima's Gen 2 modules and a new automatic transmission model and data

- Option to run either a simple drive cycle or a more involved test procedure, such as the FTP or combined city/highway cycles for fuel economy and emissions

- An energy usage figure to let the user see where every Joule of energy is used in all of the drivetrain components and obtain the component average efficiencies

- Ability to run in the MathWorks' latest version of MATLAB ${ }^{\circledR} 5.2$ and Simulink ${ }^{\circledR} 2.2$ (previous version of ADVISOR only worked in ML 4.2/SL 1.2)

\section{Easy-to-Use Graphical User Interface}

The most striking difference between older versions of ADVISOR and the new ADVISOR 2.0 is theGUI, which was written by NREL in the latest MATLAB ${ }^{\circledR} /$ Simulink $^{\circledR}$ environment. ADVISOR provides straightforward access to many powerful analysis functions through its easy-to-use GUI. The following descriptions of the three main GUI pages explain the wide array of features that are available for configuring a vehicle, conducting a simulation, and analyzing the results.

\section{Vehicle Input Page}

The layout of this screen is typical of all 3 GUI screens, in that the left-hand side of the window is the graphical representation of vehicle information; the right-had side is where the user takes action. On the right-hand side of the screen, the user specifies what he wants to see and do to the vehicle, vehicle, and controls the next action for ADVISOR to take. For example, on the vehicle input screen (see Figure 1), the picture in the upper left serves as a graphical indication of which 


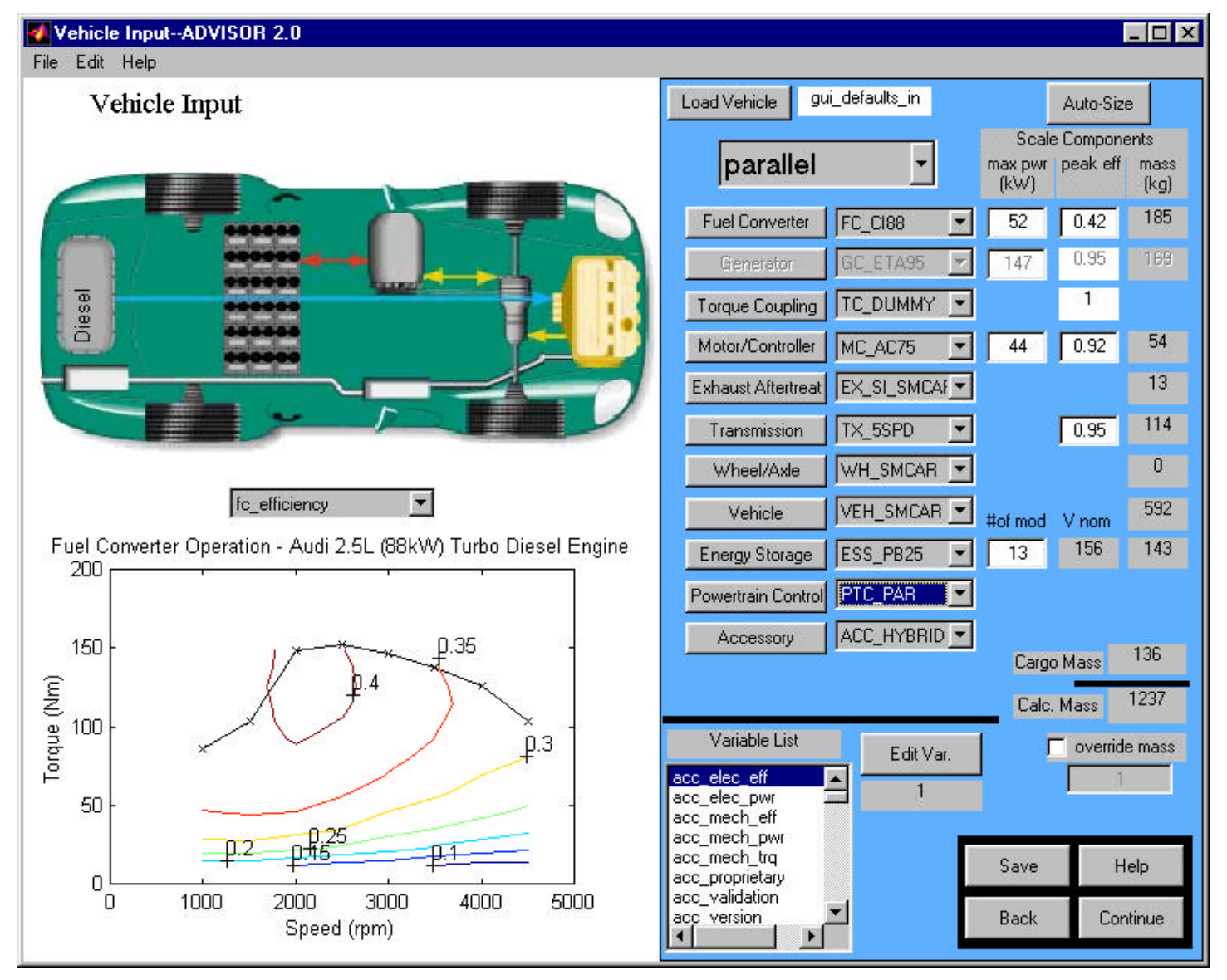

Figure 1. ADVISOR 2.0 Vehicle Input Screen

vehicle configuration has been selected (conventional, series, parallel, fuel cell, or electric vehicle). The user-selectable graphs in the lower left allow the user to immediately view the performance information on the components that have been selected, such as efficiency contours for the engine and motor, emissions contours, and performance graphs for the batteries.

On the right-hand portion of the vehicle input screen, the user has control over what type of vehicle is simulated and the details of all the components that make up the drive system. Each component has a pull-down menu that allows different components to be selected from the ADVISOR library. The two columns of numbers under the "maximum power" and "peak efficiency" headings initially indicate these values from the data files, but typing in a new number causes the GUI to linearly rescale the entire map to match that peak efficiency while preserving the map's original shape. For example, entering in a 0.45 rather than the existing 0.42 in the engine peak efficiency would allow the user to examine the impact of a hypothetical engine that could achieve a $45 \%$ peak efficiency rather than $42 \%$.

Just above these columns is an "auto-size" button that simplifies the task of iteratively sizing drivetrain components (engine, motor, and batteries) to meet user-defined minimum performance requirements of acceleration and gradeability. For parallel vehicles, the auto-size function also 
allows the user to select the degree of hybridization, which is reflected in the relative sizing of the engine, motor, and batteries.

Finally, the user can modify any scalar parameter that ADVISOR defines on the MATLAB workspace through the variable list. Because the total vehicle test mass is a parameter that is often desirable to override in various "what-if" scenarios, it is brought to the top level and can be overridden with a single mouse click and by entering in the new mass. Vehicle input files can also be saved; they store the names of the component files selected and all scaling and override settings to allow the user to recreate results at a future time or share input settings with a colleague.

\section{Simulation Setup Page}

The second of the three ADVISOR 2.0 GUI screens is the Simulation Setup screen (Figure 2). The primary decision for the user on this screen is whether to run a single cycle (and which one) or a test procedure, which can consist of special initial conditions, multiple cycles, and significant post processing (such as the test procedure to determine combined city/highway fuel economy).

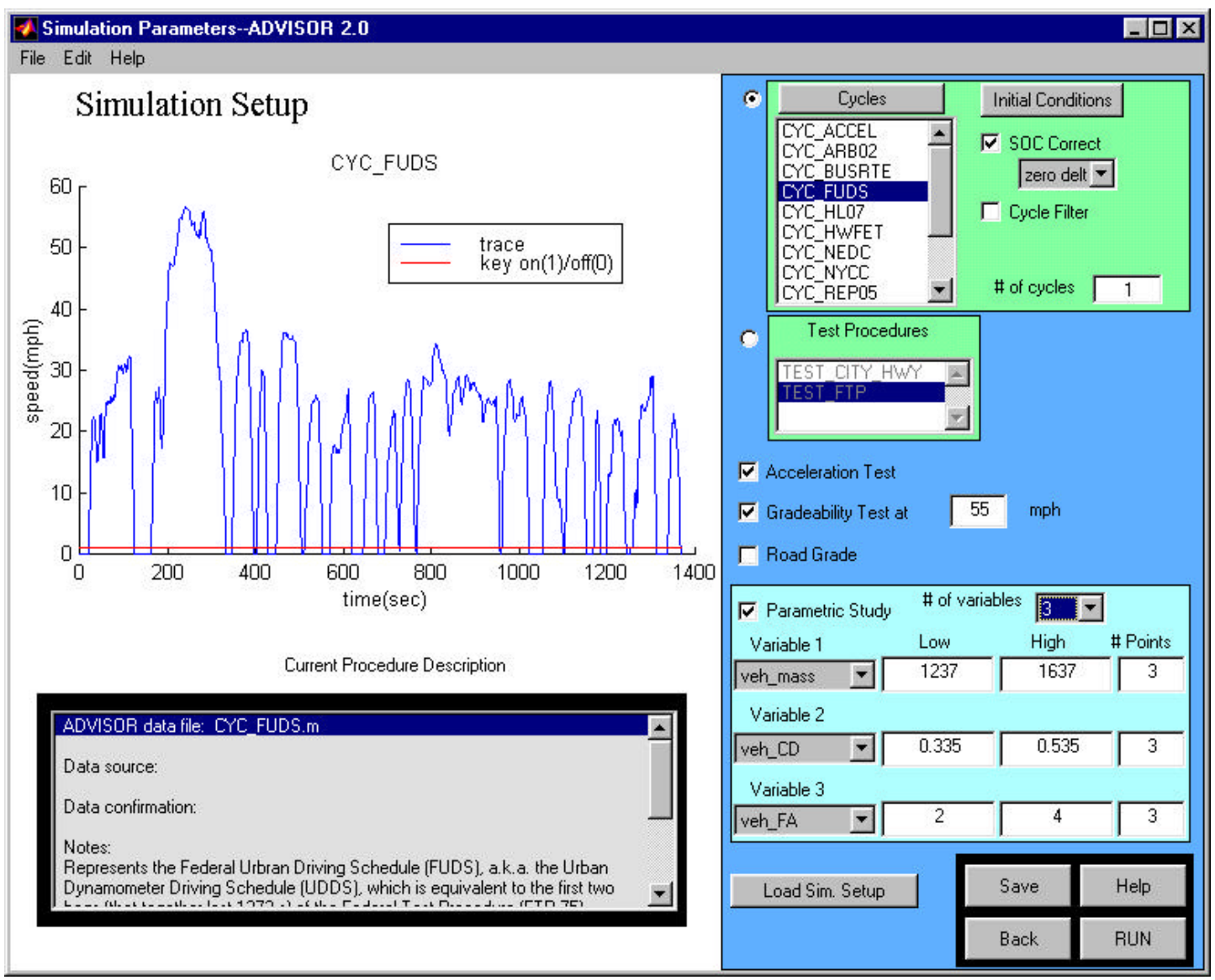

Figure 2. ADVISOR 2.0 Simulation Setup Screen 
If the single cycle option is chosen, initial conditions (primarily thermal and battery) can be set, and for hybrids the type of battery SOC correction routine can also be selected. The two SOC correction options available are a zero-delta or a linear correction routine. The zero-delta routine iterates on the initial SOC until the final SOC is within some tolerance $(0.5 \%)$, and the linear correction routine starts the battery at both its extreme high and low SOC, and then performs a linear interpolation to estimate the fuel economy at the zero-delta SOC crossing. Additionally, gradeability and acceleration tests can be selected for evaluation.

Finally, because parametric studies are often useful to explore the design space of a given vehicle, ADVISOR 2.0 allows the option of doing a 1-, 2-, or 3-parameter design sweep of any scalar value on the workspace. This allows the sensitivity of a vehicle to its various input parameters to be evaluated, not only on fuel economy, but also on performance.

\section{Results Page}

The Results Page (Figure 3) is the last of the three major ADVISOR screens. This page allows the user to see the summary results of fuel economy, emissions, acceleration, and gradeability on the right-hand side, and plots of any of the time-dependent variables that the simulation puts onto the workspace on the left-hand side.

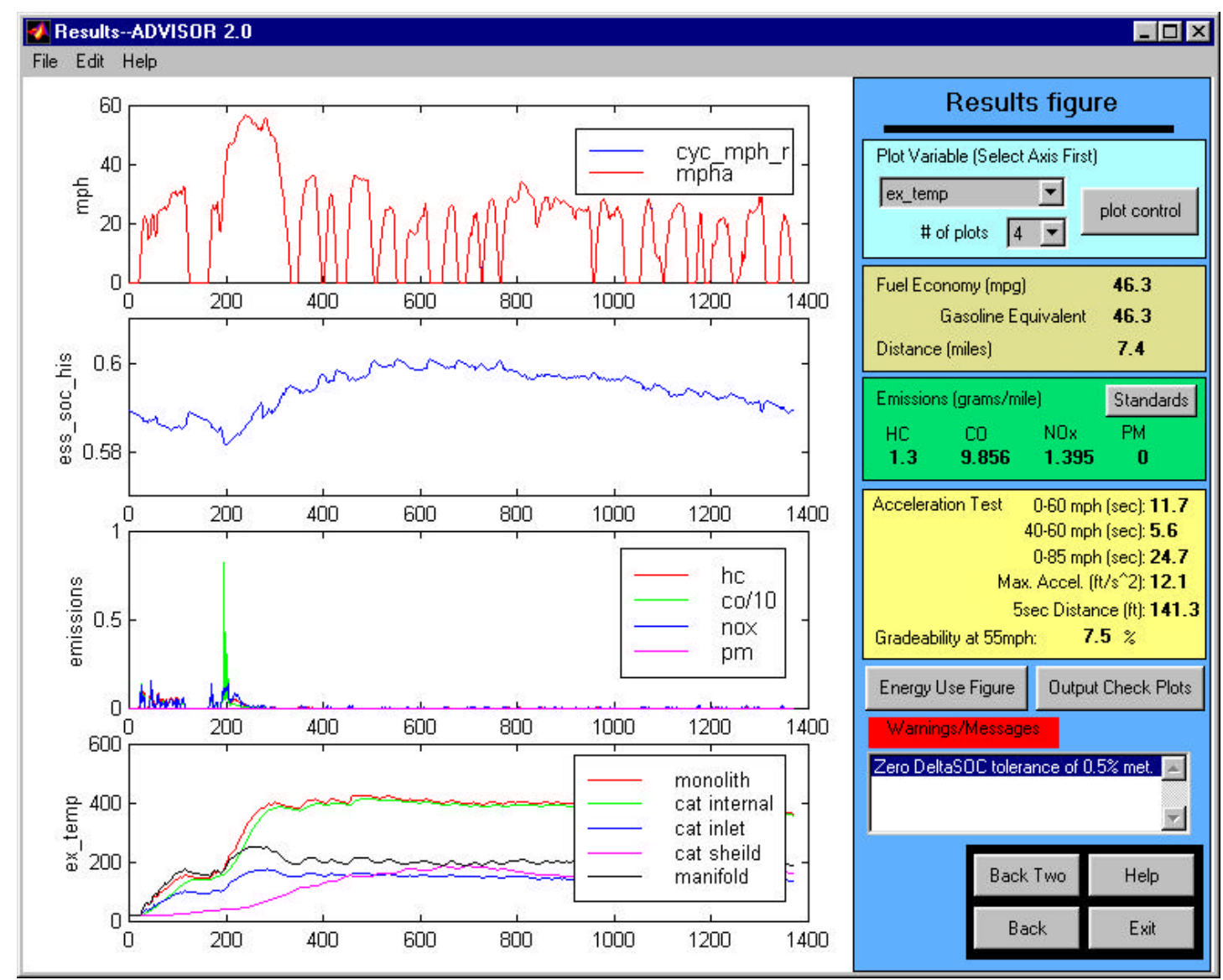

Figure 3. ADVISOR 2.0 Results Screen 
The results screen has separate pop-up windows if test procedures are selected rather than single cycles. ADVISOR 2.0 allows full usage of the built-in plotting features of MATLAB including zoom, layering multiple curves on the same graph, and applying gridlines. In Figure 3, which shows a sample Results Screen, you can see four plots that were picked as representative plots: vehicle speed, battery SOC, regulated emissions, and temperatures at various places within the exhaust system.

There are two action buttons that pull up an energy usage figure and a series of diagnostic plots. The energy usage figure tracks all of the energy through the drivetrain and where it is used and performs an energy balance to make sure that there is no unaccounted-for energy. On all screens, there is a 'HELP' button that takes the user directly to the browser-viewable documentation for more information.

\section{New Exhaust Emissions Modeling Methodology}

One of the major improvements in ADVISOR 2.0 is a much more detailed and accurate methodology for predicting tailpipe emissions than that used in previous versions of ADVISOR. The old approach used a simple exponential curve fit of typical warmup and cooldown versus time, based on conventional vehicle tests on a Federal Test Procedure (FTP) cycle [4]. The new approach uses a detailed thermal model of the exhaust aftertreatment system to predict the tailpipe emissions.

The prediction of tailpipe emissions is based on the fuel converter (an internal combustion engine, for example) emissions multiplied by the catalyst conversion efficiency. The catalyst conversion efficiency data are a function of temperature, and the temperature is calculated from a detailed thermal model of the catalytic converter system.

The converter thermal model uses the outputs from the fuel converter as its inputs: the exhaust gas flow rate and engine-out temperature. The exhaust gas loses heat to the exhaust manifold and downpipe prior to reaching the catalytic converter. The catalytic converter is modeled via a four-node lumped capacitance model including 1) monoliths, 2) inner steel shell, 3) outer shell, and 4) inlet/outlet pipes. Heat exchange from the gas to the converter nodes, between converter nodes, and from the converter to the ambient was modeled via appropriate conduction, convection, and radiation equations. Within the converter, the heat of catalysis is estimated based on the mass flow rate $(\mathrm{g} / \mathrm{s})$ of each emission component (hydrocarbons [HC], carbon monoxide $[\mathrm{CO}]$, oxides of nitrogen $\left[\mathrm{NO}_{\mathrm{x}}\right.$, ] and particulate matter $[\mathrm{PM}]$ ) being catalyzed. This heat adds to the rate of converter warmup. Having an accurate prediction of the actual catalyst temperature allows the catalytic conversion efficiency to be determined from the empirical lookup vector, and it is then multiplied by the engine-out emissions to determine tailpipe emissions.

This detailed thermal model of the exhaust aftertreatment system will enable much more flexibility in investigating aftertreatment options. Recently, NREL and Benteler Automotive Corp. used this thermal model as part of ADVISOR to look at the emissions reduction capability of the BENCHMARC vacuum-insulated catalytic converter using CARB cycles and "realworld" driving statistics [5]. 


\section{ADVISOR 2.0 Software Availability}

ADVISOR 2.0 is available on a new vehicle systems analysis Web site, located at http://www.ctts.nrel.gov/analysis. After filling out a brief User Access Form online, the user may download the software ( $2 \mathrm{MB})$ free of charge. This allows NREL to automatically notify users by e-mail messages when updates are posted to the Web site. The software is copyrighted by DOE/MRI/NREL simply to protect the integrity of the code because the download includes the full source code, GUI, all non-proprietary data files in the ADVISOR library, and complete documentation. The MathWorks latest version of MATLAB ${ }^{\circledR}$ and Simulink ${ }^{\circledR}$ are both required to be able to run ADVISOR. Besides allowing visitors to download ADVISOR 2.0, the Web site also contains additional resources:

- An ADVISOR technical support area

- A forum for asking questions and exchanging ADVISOR data files

- Information about the NREL Vehicle Systems Analysis Team

- A reading room with all the papers and presentations that the group has produced

- Further detail on many of the applications of ADVISOR that have been summarized in this paper.

\section{Future Work}

ADVISOR 2.0 is continuously evolving to meet the demands of changing technology and customer requirements. Benchmarking and validation activities will continue as the models and data continue to evolve. Our partners in industry and at other national labs are key to helping ensure the accuracy of the models and input data through testing and comparison with ADVISOR's predictions.

Improving the breadth and depth of models available in the library is also another priority. For instance, we are currently populating the model with improved diesel engine fuel usage and emissions maps. In order to be able to better analyze the impacts of fuel cell technology on advanced vehicles, we will be adding a link to a more in-depth fuel cell simulator, ANL's GCTools, as well as including a fuel cell model being developed by Virginia Tech. The NREL team will also continue to add new control strategies for hybrid vehicles, in particular to improve the flexibility to model many different types of parallel hybrid vehicles.

Finally, automated optimization will allow all vehicle configurations to take full advantage of the potential benefits of the components and how they are combined together. For example, the control strategy parameters could be optimized to give maximum fuel economy while limiting emissions and achieving the demanded performance of today's conventional vehicles.

\section{Conclusions}

NREL recently released ADVISOR 2.0 to the public through a new vehicle systems analysis page on the World Wide Web. NREL has applied ADVISOR to many different types of vehicle 
systems analysis problems, and is seeing the growing number of users apply ADVISOR to diverse and challenging analysis and design problems. After two months of being available on the Web, more than 100 users from all over the world have downloaded ADVISOR. The model has been benchmarked and validated with other models and with real vehicle test data. ADVISOR 2.0 has many new features, including an easy-to-use graphical user interface, a detailed exhaust aftertreatment thermal model, and complete browser-based documentation. Future revisions will add to the library of components available in ADVISOR, provide automated optimization functionality, and incorporate a more detailed fuel cell model.

\section{Acknowledgments}

NREL would like to thank the U.S. Department of Energy for continued support in the area of vehicle systems analysis and ADVISOR development.

\section{References}

1. Wipke, K., Cuddy, M., Burch, S.,"SAE HEV Test Procedure Task Force: Simulation Update," Presentation to the SAE J1711 Task Force, Feb. 24, 1998.

2. Wipke, K., Cuddy, M., Rausen, D., "Using Systems Modeling to Facilitate the PNGV Technology Selection Process," The Office of Transportation Technologies' 1997 Automotive Technology Development Customers' Coordination Meeting, October 28, 1997.

3. Senger, R., Merkle, M., Nelson, D., "Validation of ADVISOR as a Simulation Tool for a Series Hybrid Electric Vehicle, SAE Technical Paper \#981133, 1998.

4. Murrell, J., "Vehicle Powertrain Modeling," Letter Report under Consultant Agreement CCD-4-1403-01 to NREL, March 1995.

5. Burch, S., Biel, J., 'SULEV and 'Off-Cycle' Emissions Benefits of a Vacuum-Insulated Catalytic Converter, Draft paper for 1999 SAE Congress. 


\section{REPORT DOCUMENTATION PAGE}

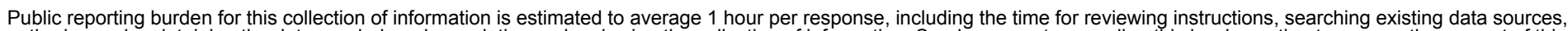

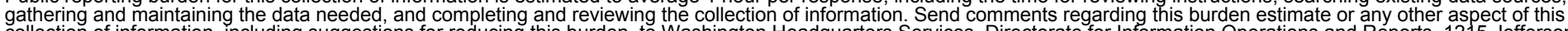

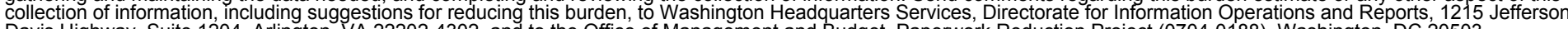
Davis Highway, Suite 1204, Arlington, VA 22202-4302, and to the Office of Management and Budget, Paperwork Reduction Project (0704-0188), Washington, DC 20503.

\begin{tabular}{|l|l|l} 
1. AGENCY USE ONLY (Leave blank) & $\begin{array}{l}\text { 2. REPORT DATE } \\
\text { March } 1999\end{array}$ & $\begin{array}{l}\text { 3. REPORT TYPE AND DATES COVERED } \\
\text { Technical paper }\end{array}$ \\
\hline
\end{tabular}

4. TITLE AND SUBTITLE

ADVISOR 2.0: A Second-Generation Advanced Vehicle Simulator for Systems Analysis

5. FUNDING NUMBERS

(C)

6. AUTHOR(S)

(TA) HV916010

K. Wipke, M. Cuddy, D. Bharathan, S. Burch, V. Johnson, T. Markel, and S. Sprik

7. PERFORMING ORGANIZATION NAME(S) AND ADDRESS(ES)

8. PERFORMING ORGANIZATION

REPORT NUMBER

National Renewable Energy Laboratory

NREL/TP-540-25928

617 Cole Blvd.

Golden, CO 80401

9. SPONSORING/MONITORING AGENCY NAME(S) AND ADDRESS(ES)

U.S. Department of Energy

1000 Independence Avenue, S.W.

Washington, D.C. 20585

\section{SUPPLEMENTARY NOTES}

\section{2a. DISTRIBUTION/AVAILABILITY STATEMENT}

National Technical Information Service

U.S. Department of Commerce

5285 Port Royal Road

Springfield, VA 22161 12b. DISTRIBUTION CODE

13. ABSTRACT (Maximum 200 words) The National Renewable Energy Laboratory has recently publicly released its second-generation advanced vehicle simulator called ADVISOR 2.0. This software program was initially developed four years ago, and after several years of in-house usage and evolution, the tool is now available to the public through a new vehicle systems analysis World Wide Web page. ADVISOR has been applied to many different systems analysis problems, such as helping to develop the SAE J1711 test procedure for hybrid vehicles and helping to evaluate new technologies as part of the Partnership for a New Generation of Vehicles (PNGV) technology selection process. The model has been and will continue to be benchmarked and validated with other models and with real vehicle test data. After two months of being available on the Web, more than 100 users have downloaded ADVISOR. ADVISOR 2.0 has many new features, including an easy-to-use graphical user interface, a detailed exhaust aftertreatment thermal model, and complete browser-based documentation. Future work will include adding to the library of components available in ADVISOR, including optimization functionality, and linking with a more detailed fuel cell model.

\section{SUBJECT TERMS}

Vehicle systems analysis, computer modeling, advanced vehicle development

15. NUMBER OF PAGES 10

16. PRICE CODE
17. SECURITY CLASSIFICATION OF REPORT
18. SECURITY CLASSIFICATION OF THIS PAGE
19. SECURITY CLASSIFICATION OF ABSTRACT
20. LIMITATION OF ABSTRACT 